\title{
Measuring bothersome menopausal symptoms: development and validation of the MenoScores questionnaire
}

\author{
Kamma Sundgaard Lund ${ }^{1 *}$ (D), Volkert Dirk Siersma ${ }^{2}$, Karl Bang Christensen ${ }^{3}$, Frans Boch Waldorff ${ }^{4}$
} and John Brodersen ${ }^{1,5}$

\begin{abstract}
Background: The experience of menopausal symptoms is common and an adequate patient-reported outcome measure is crucial in studies where women are treated for these symptoms. The aims of this study were to identify a patient-reported outcome measure for bothersome menopausal symptoms and, in the absence of an adequate tool, to develop a new measure with high content validity, and to validate it using modern psychometric methods.

Methods: The literature was reviewed for existing questionnaires and checklists for bothersome menopausal symptoms. Relevant items were extracted and subsequently tested in group interviews, single interviews, and pilot tests. A patient-reported outcome measure was drafted and completed by 1504 women. Data was collected and psychometrically validated using item-response theory Rasch Models.

Results: All questionnaires identified in the literature lacked content validity regarding bothersome menopausal symptoms and none were validated using item-response theory. Our content validation resulted in a draft measurement encompassing 122 items across eight domains. Following psychometrical validation, the final version of our patient-reported outcome measure, named the MenoScores Questionnaire, encompassed 51 items, including one single item, covering 11 scales.

Conclusion: Menopausal symptoms are multidimensional with some symptoms unquestionably related to the menopausal transition. We identified four constructs of importance: hot flushes, day-and-night sweats, general sweating, and menopausal-specific sleeping problems. The MenoScores Questionnaire is condition-specific with high content validity and adequate psychometrical properties. It is designed to measure bothersome menopausal symptoms and all scales are developed and psychometrically validated using item-response theory Rasch Models.
\end{abstract}

Trial registration: Approved by the Danish Data Agency (J.nr. 2015-41-4057). Ethics Committee approval was not required.

Keywords: Questionnaire, Scale validation, Psychometrics, Item response theory, Rasch analysis, Patient-reported outcome measures, Menopause, Menopausal symptoms

\footnotetext{
* Correspondence: kaml@sund.ku.dk

${ }^{1}$ Section of General Practice, Department of Public Health, University of

Copenhagen, Øster Farimagsgade 5, Q, P.O. Box 2099, 1014 Copenhagen K,

Denmark

Full list of author information is available at the end of the article
}

(c) The Author(s). 2018 Open Access This article is distributed under the terms of the Creative Commons Attribution 4.0 International License (http://creativecommons.org/licenses/by/4.0/), which permits unrestricted use, distribution, and reproduction in any medium, provided you give appropriate credit to the original author(s) and the source, provide a link to the Creative Commons license, and indicate if changes were made. The Creative Commons Public Domain Dedication waiver (http://creativecommons.org/publicdomain/zero/1.0/) applies to the data made available in this article, unless otherwise stated. 


\section{Background}

Menopause is the cessation of women's menstruation and can be determined retrospectively 12 months after the final menstrual period (FMP) [1, 2]. On average, women experience the menopausal transition in their mid-to-late forties [1] and the FMP in their early fifties, with large variations $[1,3,4]$.

Around $75 \%$ of menopausal women experience hot flushes [5-7] and 10-20\% of postmenopausal women find these symptoms very bothersome [5]. Some women also experience night sweats, emotional vulnerability, sleeping difficulties, fatigue, headache, joint and muscle pain, cognitive changes, vaginal dryness, and loss of sexual desire [1, 5, 8-10]. Menopausal symptoms are commonly experienced for 4-5 years in the years before and after the FMP; however, for some women the duration is longer $[1,6,11]$.

Menopausal symptoms differ between cultures and ethnic groups, and also between individuals within a homogenous population [12, 13]. Therefore, measuring self-reported menopausal symptoms presents a challenge, and so does the distinction between menopausal symptoms and the symptoms of aging. Several questionnaires regarding menopausal symptoms exist. However, to help women who are bothered by menopausal symptoms it requires a PROM that focuses solely on the bothersome symptoms. Such a PROM must also possess high content validity as well as adequate psychometric properties. Item response theory Rasch models is preferred when establishing ideal measurement psychometric properties such as unidimensionality, invariance (specific objectivity or no differential item functioning), statistical sufficiency and additivity [14-16]. The aims of this study are threefold: 1) To review existing questionnaires and symptoms checklists (which we also refer to as questionnaires) measuring bothersome menopausal symptoms, and, if we cannot identify an adequate existing questionnaire from the literature search then: 2) To develop a patient-reported outcome measure (PROM) for bothersome menopausal symptoms with high content validity, and: 3) To validate this new PROM for dimensionality, invariance, known-groups validity, and reliability using modern psychometric methods.

\section{Methods}

The study took place in Denmark and was divided into three phases: 1) a literature review; 2) qualitative interviews securing high face and content validity; 3) a validation survey where the draft PROM was distributed cross-sectionally and the data analyzed using classical test theory (CTT) and item response theory (IRT) models, securing high construct validity of the final PROM.

\section{Phase 1:Literature review}

A literature search in PubMed, Embase, and the Cochrane Library was conducted at the end of 2014 and early 2015 to identify existing questionnaires encompassing menopausal symptoms. We also consulted gynaecologists and general practice specialists to locate relevant questionnaires. We included questionnaires that contained at least one item referring to a bothersome menopausal symptom. Questionnaires on the quality of life (i.e. no items referring to specific menopausal symptoms) or concerning interference with or reaction to menopausal symptoms were not included. Questionnaires had to be freely available and written in English, Swedish, Norwegian or Danish. To be interpreted as adequate, the identified questionnaires should have high content validity encompassing items that were up-todate, not double-barrelled, or ambiguous. Moreover, the psychometric properties of the questionnaires should be assessed using IRT.

None of the identified questionnaires fulfilled all the above criteria. Therefore, we extracted an item-pool encompassing unique items about solely bothersome menopausal symptoms from the identified questionnaires. The meaningful content of relevant items was identified and assessed for redundancy, double-barrelled items were divided into separate items, and ambiguous items were rephrased. The items' response options were not transferred [17]. The subject matter of these items was translated into Danish ad-hoc by KSL and JB. The unique items were grouped into domains by KSL based on clinical experience and the literature, and these were subsequently reviewed by JB. Any discrepancies were discussed until we reached consensus.

\section{Phase 2: Qualitative interviews}

To test the content validity (content relevance and content coverage) and the understandability of the unique items, two group interviews were conducted with women bothered by menopausal symptoms. The group interviews were audio-recorded, they lasted for two hours, and were moderated by KSL and JB. The first part of the interview was an open-ended discussion about bothersome menopausal symptoms. If new themes (suggested domains) were revealed in the discussion, we generated new items covering these themes using the women's verbatim expressions from the audio recordings (see below). These new items were tested in the following group or in single interviews (see below). In the second part of the group interviews, the women were asked to assess if they found the subject matter of the unique items relevant. Items found irrelevant were deleted from the unique item-pool and, in case of lack of content coverage, new items were generated. We subsequently asked the women to which of the stated themes 
(suggested domain), their symptoms belonged. A draft PROM was created after the first group interview. At the end of the second group interview, the women were asked to complete the draft PROM. The themes (suggested domains), a recall period, and suggestions for response options were discussed. Instructions were tested for understandability.

Some symptoms postulated to be caused by menopause could also be caused by aging, therefore a global item was developed: "Have you, within the past three months, been bothered by menopausal symptoms?", with four response options: "no, not at all", "yes, a bit", "yes, quite a bit", or "yes, a lot". Later, this global item was used to evaluate the association between women with and without bothersome menopausal symptoms and the scales' ability to discriminate between the four groups in the global item: none, mild, moderate, or severe bothersome menopausal symptoms.

The draft PROM was further tested for functionality, understandability, and content validity in four single interviews conducted by KSL. The women included in these interviews were all bothered by menopausal symptoms. A paper version of the draft PROM was tested in the first two interviews and an online draft version was tested in the two final interviews. If any problems were revealed, they were corrected between interviews.

Finally, the online draft PROM was tested for functionality (including the response option) and understandability in four individual pilot tests, followed by a short interview, among women aged 50-64 where two of the women were bothered by menopausal symptoms.

The group and single interviews were audio-recorded and we measured the time taken to complete the PROM. Notes and important citations were listed during the interviews. After each interview the recording was audited by KSL and used when the key issues and results from the interviews were analyzed.

\section{Phase 3: Validation survey and analysis}

The final draft PROM was distributed by a link (SurveyXact) in emails, social media (Facebook groups for women), project research homepage [18], general practices, and the women's lifestyle magazine "Liv" [19] (through their online newsletter and Facebook page). Women aged 45-65 years, with and without bothersome menopausal symptoms, were asked to complete the PROM.

Reliability and validity To secure adequate psychometric properties of the final PROM we conducted Rasch analysis on the data collected verifying if items in each suggested domain fitted a partial credit Rasch model for polytomous items [20]. We tested differential item functioning (DIF) [21, 22], i.e. if items performed differently depending on the variables: occupation, education, living (living alone), smoking, BMI, age, hormonal intrauterine device, bilateral ovariectomized, hysterectomized, having menstruation within the past year. Local dependence (LD) was also evaluated [15, 23], i.e. whether items were correlated beyond what could be expected by measuring the same underlying construct using item screening and log-linear Rasch model tests [24, 25]. Where evidence of DIF and/or LD was disclosed, a log-linear Rasch model was considered indicating a scaling solution with desirable measurement properties [14]. Andersen's conditional likelihood ratio test $\left(\mathrm{CLR}-\mathrm{X}^{2}\right)$ was used to evaluate the overall model fit [26] and individual item fit was assessed by comparing observed and expected rank correlation between the item and rest-score (sum of other items in scale) [27]. Items that demonstrated the most problematic properties and/or poor fit were deleted stepwise from the scales, until fit of the Rasch model was achieved. Items with misfit but high face and content validity it were kept as a single item. Cronbach's alpha was used as a measure of reliability $[28,29]$. The Benjamini-Hochberg procedure was used to account for multiple testing [30].

The sum-scores of the resulting Rasch-fitting scales (see below) was tested by comparison to the global item. For each of the four categories of the global item the means and standard deviations (SD) of the sum-scores were calculated and compared using ANOVA; also, the order of the means in a sum-score should reflect the order of the categories of the global item. We calculated the number of subjects needed in a hypothetical randomized trial to find, with $80 \%$ power, the difference between the means corresponding to the two last categories of the global item in a t-test with a significance level of 5\%; low numbers indicate a high discriminating ability. We used SAS v9.4 and DIGRAM v3.05.3 software.

The study was approved by the Danish Data Agency (J.nr. 2015-41-4057). Ethics Committee approval was not required.

\section{Results}

\section{Phase 1}

We identified 15 questionnaires written in English or Danish in the literature search, many of which referred to each other: Kupperman index [31, 32], Modified Blatt-Kupperman index [33, 34], Greene (1976) [35], Greene climacteric scale (GCS) [36], WHQ [37, 38], MENQOL [39], MENQOL-intervention [40], Menopause symptom list (MSL) [41], Menopause rating scale (MRS) [42], 10-items Cervantes scale (CS-10) [43], Menopause health state classification [44], Menopause health questionnaire [4], Neugarten and Kraines [45], Hvas et al. [46], MQOL [47]. None of the identified 
questionnaires were adequate in relation to all our adequacy criteria: some were not up-to-date [31, 35, 45], some not sufficiently validated $[31,32,46]$ or with missing information about validation [4, 44]. Some had ambiguous or double-barrelled items [35, 36, 42], and some were primarily designed to measure quality of life in menopausal women [39, 40, 47] or economic evaluations of the impact of menopause [44], and not just the level of bothersome menopausal symptoms. None were assessed using IRT.

These questionnaires had in total 356 items, of which 126 were unique items divided into five domains (Additional file 1: Appendix 1).

\section{Phase 2}

The first group interview included five women (aged 50-63 years), and the second included four women (aged 49-59 years).

In the two group interviews $95(75.4 \%)$ of the 126 items were endorsed and 27 new items (five of these due to double-barrelled items) and three new domains were generated (Additional file 1: Appendix 1). In the first group interview it was revealed that hot flushes and dayand-night sweats were experienced as two different things (constructs). Some women were bothered by hot flushes but did not experience day-and-night sweats. Others were bothered by both hot flushes and day-andnight sweats, but described it as different experiences. This was confirmed in the second group interview.

The women agreed on a three-month recall period and preferred the four response options; "no, not at all", "yes, a bit", "yes, quite a bit", or "yes, a lot" (Table 1. Item layout). In the sexual domain it was decided to create an additional response option "I do not know" for respondents not sexually active, with or without a partner. These preferences were later confirmed in the single interviews. By the end of the second group interview no new items or domains were generated.

Women interviewed individually were aged 50-52 and the women who participated in pilot testing were aged 50-64. In these interviews, almost all comments were about linguistic issues or layout suggestions and only one extra item was desired and another item perceived as redundant and deleted. At this point we achieved data

Table 1 Example of item layout and response options

Have you - within the past three months - experienced the following symptoms?

No, not Yes, a bit Yes, quite a bit Yes, a lot at all

I have had hot flushes

during the day

I have had hot flushes

during the night saturation. Finally, one woman requested a comment box at the end of the PROM. Table 2 presents the number and age of participants in the interviews. The final version of the draft PROM encompassed 122 items covering 8 domains (Additional file 2: Appendix 2) and took, on average, $10 \mathrm{~min}$ to complete.

\section{Phase 3}

Survey

Within $48 \mathrm{~h} 1511$ women had completed the draft PROM. Seven completed questionnaires were excluded; six respondents were under the age of 45 years and one respondent had ambiguous and inconsistent responses. The characteristics of the remaining 1504 respondents are listed in Tables 2 and 3.

\section{Psychometric analysis}

The analyses revealed eleven uni-dimensional scales fitting a Rasch model. One single item was retained due to high face validity.

The final PROM was named the MenoScores Questionnaire (MSQ) and the eleven scales cover the constructs: hot flushes (HF), 2 items; day-and-night sweats (DNS), 2 items; general sweating (GS), 2 items; menopausal-specific sleeping problems (MSSP), 2 items; emotional (EM), 12 items; memory (MEM), 2 items; skin-hair (SH), 8 items; physical (PHY), 8 items; abdominal (ABD), 4 items; urinal-vaginal (URIN), 4 items, and sexual (SEX), 4 items. Including the retained single item (more tired than usual) the MSQ encompasses 51 items in total. Item numbers are listed in Table 4.

\section{Vasomotor symptoms}

This suggested six-item domain showed misfit. Based on evidence of LD and results from the qualitative interviews, where hot flushes and day-and-night sweats were described as two different constructs, three two-item scales were formed. These scales all fitted a Rasch model and had no evidence of LD and were named: hot flushes (HF), day-and-night sweats (DNS) and general sweating (GS).

In the HF scale, item 4 (hot flushes during the day) showed DIF with respect to (wrt.) having menstruation within the past year $(p=0.0013)$, and item 5 (hot flushes during the night) showed DIF wrt. BMI $(p=0.0008)$. In the DNS scale, item 6 (sweats during the day) showed DIF wrt. BMI $(p<0.0001)$, and item 7 (night-sweats) showed DIF wrt. Having menstruation within the past year $(p=0.0045)$. In the GS scale there was no evidence of DIF.

\section{Sleep}

The suggested 10-item domain did not fit a Rasch model. A two-item menopausal-specific sleeping problems 
Table 2 Number and age of participants (BMS = bothersome menopausal symptoms)

\begin{tabular}{lllll}
\hline & Number & Number with/without BMS & $\begin{array}{l}\text { Age (women with BMS) } \\
\text { Mean (range) }\end{array}$ & $\begin{array}{l}\text { Age (women without BMS) } \\
\text { Mean (range) }\end{array}$ \\
\hline Group interviews & 9 & $9 / 0$ & $52.89(49-63)$ & - \\
Single interviews & 4 & $4 / 0$ & $50.75(50-52)$ & - \\
Pilot test & 4 & $2 / 2$ & $52(50-54)$ & $63(62-64)$ \\
$\begin{array}{l}\text { Survey (cross } \\
\text { sectional) }\end{array}$ & 1504 & $1073 / 431$ & $51.97(45-65)$ & $50.69(45-65)$ \\
\hline
\end{tabular}

(MSSP) scale was found to fit a Rasch model with no evidence of DIF or LD.

\section{Emotional}

The suggested 36-item domain did not fit a Rasch model. We omitted poor fitting items and found a 12item EM scale (items 22, 27, 30, 31, 33, 34, 40, 43, 45, $47,48,53)$ with adequate fit to the partial credit Rasch model, but with substantial evidence of LD. The LD suggests four clusters of items: depression (three items: 22 [been depressed], 27 [mood swings], 34 [worried about nervous breakdown]); anxiety (three items: 30 [felt anxiety], 31 [felt nervous], 33 [needlessly worried]); social (two items: 40 [less confidence], 45 [felt isolated]), and energy (four items: 43 [no energy to socialize], 47 [do less], 48 [can accomplish less] 53 [difficulty concentrating]). No satisfactory log-linear Rasch model could be identified.

We analyzed items 54 and 55 separately because of high content validity and because the content seemed different from the remaining items. They formed the Memory (MEM) scale where no DIF or LD was revealed.

\section{Skin, hair and mucosa}

This suggested 15-item domain did not fit a Rasch model, but an eight-item scale $(58,62,63,64,65,66,67$, $69)$, the skin-hair ( $\mathrm{SH})$ scale, was found to fit the loglinear Rasch model. Evidence of LD was disclosed for three item pairs: 62 (crawling feeling over the skin) and 63 (itching of the scalp); 64 (vaginal dryness) and 65 (vaginal itching); 66 (shed more hair than usual) and 67 (nails split more than usual). Item 62 showed DIF wrt. Smoking; item 64 showed DIF wrt. Age and wrt. Having menstruation within the past year, and item 65 showed DIF wrt. Having menstruation within the past year.

\section{Physical}

This suggested physical 41-item domain was divided into 3 hypothesized scales due to the content of the items: physical (PHY), 25 items; abdominal (ABD), 10 items, and urinary-vaginal (URIN), 6 items.

Physical (PHY) scale.

This 25-item scale was rejected, but a scale with eight items $(71,73,75,76,80,84,86,95)$ was found to fit the log-linear Rasch model where evidence of LD was found for the three item pairs 71 (heart palpitation) and 76 (been dizzy); 73 (headache) and 84 (neck pain); 80 (sore joints) and 86 (pins and needles in feet). Furthermore, item 73 showed DIF wrt. Age and item 80 showed DIF wrt. BMI.

\section{Abdominal $(A B D)$ scale}

This 10 -item scale was rejected, but a 4 -item scale comprising the items 77, 96, 98, and 102 was found to fit a log-linear Rasch model. In this scale, LD was found between item 77 (nausea) and item 98 (uncontrollable loss of gas). Item 96 (bloated stomach) showed DIF wrt. Age and item 98 showed DIF wrt. Education.

\section{Urinary-vaginal (URIN) scale}

The 6-item scale was rejected, but a 4-item scale comprising the four items 106, 107, 108, and 110 was obtained. Item 108 (urine smells different) showed DIF wrt. Smoking and LD was found between item 106 (need to pass urine more frequently) and 107 (sometimes leak urine), and between 108 (urine smells different) and 110 (vaginal discharge has been different).

Item 91 (more tired than usual) did not fit any of the scales. The item was also tested with the MSSP scale but without a fit to a Rasch model. Finally, the item was tested with the three related items 92, 93, and 94 but they did not fit a Rasch model. Nevertheless item 91 was retained as a single item because of its high face validity.

\section{Sexual}

Four items $(115,116,117,118)$ from this domain fitted a Rasch model and were named the sexual (SEX) scale. LD was found between the items 115 (pain during intercourse) and 116 (bleeding after intercourse). Item 115 showed DIF wrt. Age and being bilaterally ovariectomized and item 116 showed DIF wrt. Having a hormonal intrauterine device and having menstruation within the past year; while item 117 (too tired for sex) showed DIF wrt. Living alone.

The SH, ABD scales showed signs of dichotomization in the category probability curves. The SH, ABD and SEX (with the additional response option "I do not know") scales were re-tested in three single interviews 
Table 3 Characteristics of respondents (survey)

\begin{tabular}{|c|c|c|}
\hline $\begin{array}{l}\text { Characteristics/ } \\
\text { exogenous variables }\end{array}$ & $\begin{array}{l}\text { Total no. } \\
\text { (\% of total) }\end{array}$ & $\begin{array}{l}\text { Bothersome } \\
\text { menopausal symptoms } \\
\text { No. (\%) }\end{array}$ \\
\hline Total & $1504(100)$ & $1073(71.34)$ \\
\hline \multicolumn{3}{|l|}{ Age (years): } \\
\hline $45-48$ & $394(26.20)$ & 209 (53.05) \\
\hline $49-52$ & $543(36.10)$ & $417(76.80)$ \\
\hline $53-55$ & $304(20.21)$ & 264 (86.84) \\
\hline $56-60$ & 205 (13.63) & $154(75.12)$ \\
\hline $61-65$ & $58(3.86)$ & $29(50.00)$ \\
\hline \multicolumn{3}{|l|}{ BMI } \\
\hline 0-18 & $10(0.67)$ & $8(80.00)$ \\
\hline $19-24$ & $682(45.77)$ & 469 (68.77) \\
\hline $25-29$ & $518(34.77)$ & 379 (73.17) \\
\hline$\geq 30$ & 280 (18.79) & $206(73.57)$ \\
\hline Missing & 14 & \\
\hline \multicolumn{3}{|l|}{ Occupation $^{a}$} \\
\hline Yes & $1250(83.11)$ & 893 (71.44) \\
\hline No & 75 (4.99) & $50(66.67)$ \\
\hline Sick leave & 51 (3.39) & $34(66.67)$ \\
\hline Retired or similar & $128(8.51)$ & $96(75.00)$ \\
\hline \multicolumn{3}{|l|}{ Education } \\
\hline No education & $56(3.73)$ & $41(73.21)$ \\
\hline $\begin{array}{l}\text { Skilled worker, apprentice, } \\
\text { assistant nurse or likewise }\end{array}$ & $273(18.16)$ & $206(75.46)$ \\
\hline $\begin{array}{l}\text { Short higher education }{ }^{\mathrm{b}}< \\
3 \text { years }\end{array}$ & $213(14.17)$ & $167(78.40)$ \\
\hline $\begin{array}{l}\text { Medium higher education } \\
3-4 \text { years }\end{array}$ & $633(42.12)$ & 449 (70.93) \\
\hline $\begin{array}{l}\text { Long higher education > } \\
4 \text { years }\end{array}$ & $233(15.50)$ & $141(60.52)$ \\
\hline Other & $90(5.99)$ & $63(70.00)$ \\
\hline Do not know & $5(0.33)$ & $5(100)$ \\
\hline Missing & 1 & \\
\hline \multicolumn{3}{|l|}{ Living alone } \\
\hline Yes & 310 (20.78) & $214(69.03)$ \\
\hline No & $1182(79.22)$ & $851(72.00)$ \\
\hline Missing & 12 & \\
\hline \multicolumn{3}{|l|}{ Smoking } \\
\hline Yes & 238 (15.82) & $179(75.21)$ \\
\hline No & $1266(84.18)$ & 894 (70.62) \\
\hline \multicolumn{3}{|l|}{ Gynecological history } \\
\hline \multicolumn{3}{|l|}{ Hormonal intrauterine device } \\
\hline Yes & $247(16.42)$ & $144(58.30)$ \\
\hline No & $1257(83.58)$ & $929(73.91)$ \\
\hline \multicolumn{3}{|l|}{ Bilateral ovariectomized } \\
\hline Yes & $40(2.66)$ & $32(80.00)$ \\
\hline
\end{tabular}

Table 3 Characteristics of respondents (survey) (Continued)

\begin{tabular}{lll}
\hline $\begin{array}{l}\text { Characteristics/ } \\
\text { exogenous variables }\end{array}$ & $\begin{array}{l}\text { Total no. } \\
\text { (\% of total) }\end{array}$ & $\begin{array}{l}\text { Bothersome } \\
\text { menopausal symptoms } \\
\text { No. (\%) }\end{array}$ \\
\hline No & $1464(97.34)$ & $1041(71.11)$ \\
Hysterectomized & $121(8.05)$ & $95(78.51)$ \\
Yes & $1383(91.95)$ & $978(70.72)$ \\
No & $717(47.67)$ & $464(64.71)$ \\
Having menstruation within the past year \\
Yes \\
No
\end{tabular}

accupation Employed, working or studying. ${ }^{\mathrm{b}}$ higher education = education after high school or likewise

(with women age 50 to 65) and all women preferred the three-response option instead of four ("no, not at all", "yes, a bit", or "yes, a lot", plus the additional option in the SEX scale). In order to optimize model fit, the response options in these scales were reduced to the three options above (including the addition option in the SEX scale).

\section{Work and spare time}

Two-thirds of respondents were asked to complete this domain (i.e. women who claimed to be bothered by menopausal symptoms by answering "yes" to the global item). The 3-item domain fitted a Rasch model $(p=0.117)$ but items 1 and 3 with extremely poor item fit $(p=0.0001)$ and $(p=<0.0001)$. Thus, we decided to exclude this domain from the final PROM.

\section{Menstruation}

Only women who had menstruated within the past year were asked to complete this domain (approximately half of the respondents) (Table 3). This suggested 3-item domain did not fit a Rasch model $(\mathrm{p}=0.000)$ and the items were not included in the final PROM.

\section{Association (discrimination)}

The HF, DNS, GS, and MSSP scales showed best performance in discriminating between the response options of the global item (Fig. 1. HF, DNS, GS, MSSP scales). The discriminating ability is presented in Table 5 .

\section{Reliability}

The reliability of the scales was moderate to high with Cronbach's alpha values between 0.60 and 0.91 (Table 5).

Table 4 presents individual item fit and Table 5 presents fit statistics, Cronbach's alpha, and discriminating ability.

\section{Discussion}

We found that all existing questionnaires lacked content validity regarding bothersome menopausal symptoms and none were validated using IRT. Moreover, they all 
Table 4 Individual item fit

\begin{tabular}{|c|c|c|c|c|c|c|c|c|c|}
\hline Item no. & Item wording & A priori domain & Final scale & Fit to Rasch & h model & & $\begin{array}{l}\text { Fit to log } \\
\text { Rasch mo }\end{array}$ & $\begin{array}{l}\text { inear } \\
\text { del }\end{array}$ & \\
\hline & & & & Observed & Expected & $\mathrm{P}$ & Observed & Expected & $\mathrm{P}$ \\
\hline 4 & I have had hot flushes during the day & D2 - Vasomotor & $\mathrm{HF}$ & 0.824 & 0.823 & 0.9107 & 0.821 & 0.820 & 0.9157 \\
\hline 5 & I have had hot flushes during the night & D2 - Vasomotor & $\mathrm{HF}$ & 0.824 & 0.823 & 0.9107 & 0.821 & 0.820 & 0.9157 \\
\hline 6 & $\begin{array}{l}\text { I have had bouts of sweating during the } \\
\text { day }\end{array}$ & D2 - Vasomotor & DNS & 0.694 & 0.691 & 0.8768 & 0.694 & 0.691 & 0.8757 \\
\hline 7 & I have had bouts of night sweats & D2 - Vasomotor & DNS & 0.694 & 0.691 & 0.8768 & 0.694 & 0.691 & 0.8757 \\
\hline 8 & I have been sweating more than usual. & D2 - Vasomotor & GS & 0.632 & 0.633 & 0.9720 & 0.632 & 0.633 & 0.9628 \\
\hline 9 & I have had cold sweats & D2 - Vasomotor & GS & 0.632 & 0.633 & 0.9720 & 0.632 & 0.633 & 0.9628 \\
\hline 10 & $\begin{array}{l}\text { I have not been able to sleep because of } \\
\text { night sweats }\end{array}$ & D3 - Sleep & MSSP & 0.872 & 0.870 & 0.8853 & - & - & - \\
\hline 11 & $\begin{array}{l}\text { I have not been able to sleep because of } \\
\text { hot flushes }\end{array}$ & D3 - Sleep & MSSP & 0.872 & 0.870 & 0.8853 & - & - & - \\
\hline 22 & I have been depressed & D4 - Emotional & EM & 0.717 & 0.680 & 0.0360 & - & - & - \\
\hline 27 & I have had mood swings & D4 - Emotional & EM & 0.646 & 0.677 & 0.0545 & - & - & - \\
\hline 30 & I have felt anxiety & D4 - Emotional & EM & 0.690 & 0.693 & 0.9022 & - & - & - \\
\hline 31 & I have felt nervous & D4 - Emotional & EM & 0.696 & 0.680 & 0.3557 & - & - & - \\
\hline 33 & I have been needlessly worried & D4 - Emotional & EM & 0.667 & 0.678 & 0.5050 & - & - & - \\
\hline 34 & $\begin{array}{l}\text { I have been worried about having a } \\
\text { nervous breakdown }\end{array}$ & D4 - Emotional & EM & 0.727 & 0.700 & 0.1399 & - & - & - \\
\hline 40 & I have had less confidence & D4 - Emotional & EM & 0.677 & 0.687 & 0.5561 & - & - & - \\
\hline 43 & I have not had the energy to socialize & D4 - Emotional & EM & 0.671 & 0.677 & 0.7186 & - & - & - \\
\hline 45 & I have felt isolated & D4 - Emotional & EM & 0.689 & 0.693 & 0.7989 & - & - & - \\
\hline 47 & I have done less than I would like & D4 - Emotional & EM & 0.694 & 0.681 & 0.3996 & - & - & - \\
\hline 48 & I can accomplish less than I used to & D4 - Emotional & EM & 0.680 & 0.682 & 0.9221 & - & - & - \\
\hline 53 & I have had difficulty concentrating & D4 - Emotional & EM & 0.682 & 0.683 & 0.9548 & - & - & - \\
\hline 54 & My memory has been worse than usual & D4 - Emotional & MEM & 0.923 & 0.923 & 0.9841 & - & - & - \\
\hline 55 & $\begin{array}{l}\text { I have had problems with remembering } \\
\text { everyday things }\end{array}$ & D4 - Emotional & MEM & 0.923 & 0.923 & 0.9841 & - & - & - \\
\hline 58 & I have had dry skin & $\begin{array}{l}\text { D5 - Skin, hair and } \\
\text { mucosa }\end{array}$ & $\mathrm{SH}$ & 0.462 & 0.411 & 0.0273 & 0.462 & 0.351 & $\begin{array}{l}< \\
0.0001\end{array}$ \\
\hline 62 & I have had a crawling feeling over the skin & $\begin{array}{l}\text { D5 - Skin, hair and } \\
\text { mucosa }\end{array}$ & $\mathrm{SH}$ & 0.411 & 0.418 & 0.8215 & 0.409 & 0.445 & 0.2133 \\
\hline 63 & I have had itching of the scalp & $\begin{array}{l}\text { D5 - Skin, hair and } \\
\text { mucosa }\end{array}$ & $\mathrm{SH}$ & 0.436 & 0.405 & 0.2111 & 0.436 & 0.416 & 0.4045 \\
\hline 64 & I have had vaginal dryness & $\begin{array}{l}\text { D5 - Skin, hair and } \\
\text { mucosa }\end{array}$ & $\mathrm{SH}$ & 0.418 & 0.431 & 0.5544 & 0.417 & 0.463 & 0.0378 \\
\hline 65 & I have had vaginal itching & $\begin{array}{l}\text { D5 - Skin, hair and } \\
\text { mucosa }\end{array}$ & $\mathrm{SH}$ & 0.475 & 0.405 & 0.0131 & 0.474 & 0.478 & 0.8649 \\
\hline 66 & I have shed more hair than usual & $\begin{array}{l}\text { D5 - Skin, hair and } \\
\text { mucosa }\end{array}$ & $\mathrm{SH}$ & 0.417 & 0.421 & 0.8541 & 0.417 & 0.418 & 0.9889 \\
\hline 67 & My nails split more than usual & $\begin{array}{l}\text { D5 - Skin, hair and } \\
\text { mucosa }\end{array}$ & $\mathrm{SH}$ & 0.364 & 0.425 & 0.0128 & 0.371 & 0.423 & 0.0337 \\
\hline 69 & I have more body hair growth & $\begin{array}{l}\text { D5 - Skin, hair and } \\
\text { mucosa }\end{array}$ & $\mathrm{SH}$ & 0.333 & 0.412 & 0.0062 & 0.333 & 0.346 & 0.6786 \\
\hline 71 & I have had heart palpitations & D6 - Physical & $\mathrm{PHY}$ & 0.468 & 0.491 & 0.3039 & 0.468 & 0.491 & 0.3039 \\
\hline 73 & I have had headache & D6 - Physical & $\mathrm{PHY}$ & 0.461 & 0.496 & 0.0934 & 0.461 & 0.496 & 0.0934 \\
\hline 75 & I have had a blind spot in front of my eye & D6 - Physical & $\mathrm{PHY}$ & 0.510 & 0.510 & 0.9896 & 0.510 & 0.510 & 0.9896 \\
\hline 76 & I have been dizzy & D6 - Physical & $\mathrm{PHY}$ & 0.533 & 0.485 & 0.0396 & 0.533 & 0.485 & 0.0396 \\
\hline
\end{tabular}


Table 4 Individual item fit (Continued)

\begin{tabular}{|c|c|c|c|c|c|c|c|c|c|}
\hline Item no. & Item wording & A priori domain & Final scale & Fit to $R$ & h model & & $\begin{array}{l}\text { Fit to I } \\
\text { Rasch }\end{array}$ & $\begin{array}{l}\text { inear } \\
\text { del }\end{array}$ & \\
\hline 80 & One or more of my joints has been sore & D6 - Physical & $\mathrm{PHY}$ & 0.528 & 0.513 & 0.4367 & 0.528 & 0.513 & 0.4367 \\
\hline 84 & I have had neck pain & D6 - Physical & PHY & 0.530 & 0.518 & 0.5332 & 0.530 & 0.518 & 0.5332 \\
\hline 86 & I have had pins and needles in my feet & D6 - Physical & $\mathrm{PHY}$ & 0.546 & 0.527 & 0.4502 & 0.546 & 0.527 & 0.4502 \\
\hline 95 & I have been more clumsy than usual & D6 - Physical & PHY & 0.505 & 0.506 & 0.9606 & 0.505 & 0.506 & 0.9606 \\
\hline 77 & I have had nausea & D6 - Physical & $A B D$ & 0.421 & 0.464 & 0.1331 & 0.421 & 0.464 & 0.1331 \\
\hline 96 & My stomach has tended to be bloated & D6 - Physical & $A B D$ & 0.500 & 0.476 & 0.2837 & 0.500 & 0.476 & 0.2837 \\
\hline 98 & I have had uncontrollable loss of gas & D6 - Physical & $A B D$ & 0.507 & 0.472 & 0.1474 & 0.507 & 0.472 & 0.1474 \\
\hline 102 & My stool has been loose & D6 - Physical & $A B D$ & 0.453 & 0.466 & 0.6507 & 0.453 & 0.466 & 0.6507 \\
\hline 106 & $\begin{array}{l}\text { I need to pass urine more frequently than } \\
\text { usual }\end{array}$ & D6 - Physical & URIN & 0.532 & 0.481 & 0.03241 & 0.532 & 0.492 & 0.0975 \\
\hline 107 & I sometimes leak urine & D6 - Physical & URIN & 0.459 & 0.474 & 0.55320 & 0.459 & 0.489 & 0.2257 \\
\hline 108 & My urine has smelled different & D6 - Physical & URIN & 0.511 & 0.482 & 0.28580 & 0.511 & 0.462 & 0.0770 \\
\hline 110 & My vaginal discharge has been different & D6 - Physical & URIN & 0.419 & 0.483 & 0.03539 & 0.419 & 0.477 & 0.0569 \\
\hline 115 & I have had pain during intercourse & D7 - Sexual & SEX & 0.701 & 0.629 & 0.0010 & 0.701 & 0.676 & 0.2232 \\
\hline 116 & I have had bleeding after intercourse & D7 - Sexual & SEX & 0.714 & 0.699 & 0.5665 & 0.714 & 0.764 & 0.0222 \\
\hline 117 & I have been too tired for sex & D7 - Sexual & SEX & 0.579 & 0.580 & 0.9703 & 0.579 & 0.550 & 0.1721 \\
\hline 118 & I have had difficulty achieving an orgasm & D7 - Sexual & SEX & 0.535 & 0.576 & 0.0554 & 0.535 & 0.544 & 0.6740 \\
\hline 91 & I have felt more tired than usual & D6 - Physical & $\begin{array}{l}\text { Single } \\
\text { item }\end{array}$ & - & - & - & - & - & - \\
\hline
\end{tabular}

$\mathrm{HF}=$ hot flushes (2 items), DNS = day-and-night sweats (2 items), GS = general sweating (2 items), MSSP = menopausal-specific sleeping problems (2 items), EM = emotional (12 items), MEM = memory (2 items), $\mathrm{SH}=$ skin-hair (8 items), $\mathrm{PHY}=$ physical (8 items), $\mathrm{ABD}=$ abdominal $(4$ items), URIN = urin-vaginal $(4$ items), SEX = sexual (4 items)

regarded hot flushes and day-and-night sweats as a single construct, which this study could not confirm. We found that the suggested vasomotor domain was threedimensional concluding that hot flushes and day-andnight sweats are two different constructs. This was revealed in the qualitative interviews and confirmed by the Rasch analysis. Furthermore, these findings were confirmed when screening potential participants for a current randomized controlled trial (RCT) [48]. This study also revealed that only some symptoms are unquestionably related to the menopausal transition and four constructs are of importance when measuring bothersome menopausal symptoms: hot flushes, dayand-night sweats, general sweating and menopausalspecific sleeping problems.

A strength of this study is the combination of rigorous qualitative and quantitative processes. Through the qualitative interviews we secured high content validity. Subsequently we used Rasch models to assess if the suggested domains behaved psychometrically as we expected. Another strength is the assessment of discriminating ability. Using the responses to the global item, in relation to the responses to the remaining items, we assessed how well the individual scales within the MSQ discriminated between the response options of the global item. We found the HF, DNS, GS and MSSP scales performed best in discriminating. Our interpretation of this is that only these constructs (HF, DNS, GS, MSSP) are unquestionably related to the menopausal transition. Many other symptoms may be, more or less, caused by aging.

A limitation could be that as the data was collected cross-sectionally, test-retest analysis is not reported. Women with bothersome menopausal symptoms report fluctuations in their symptoms from day-to-day. Therefore, a test-retest with a 2-week interval would not be meaningful. Instead we assessed the internal consistency of the scales using Cronbach's alpha. A further limitation is the broad sampling procedure which makes it difficult to know exactly what population the sample is representative of, due to the element of self-selection inherent in survey data using web-based enrolment. The fact that Rasch validation is performed without distributional assumptions mitigates this challenge.

We identified DIF and LD in some of the final scales which may limit MSQ's applicability in some situations. Items 4 and 5 from the HF scale and items 6 and 7 from the DNS scale all possessed DIF. Nevertheless, these items were maintained because of their high face validity. If the developed scales are used in a RCT, DIF is far less problematic because any exogenous variables will presumably be equally distributed among the randomized 

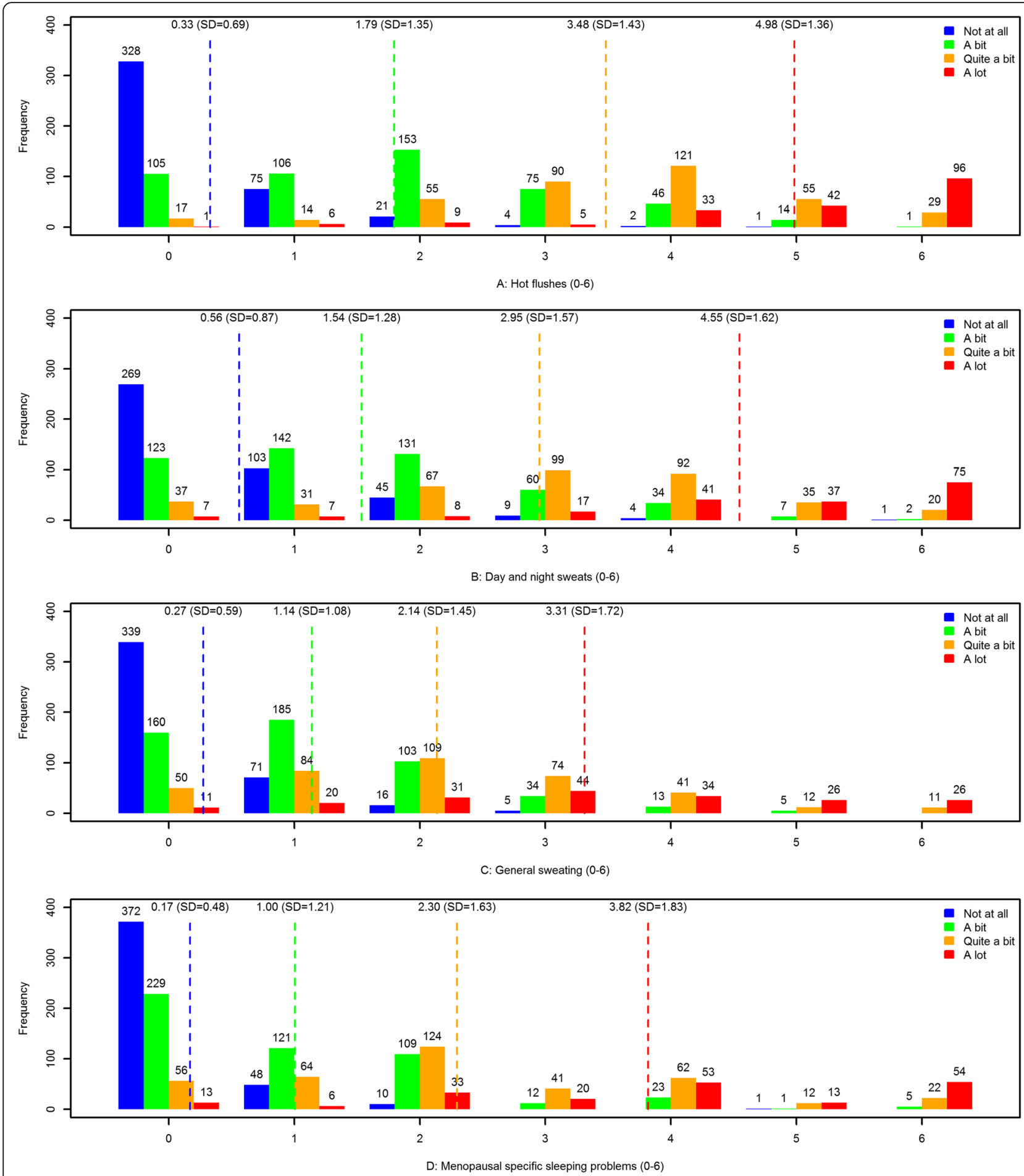

Fig. $1 \mathrm{HF}, \mathrm{DNS}, \mathrm{GS}, \mathrm{MSSP}$ scales

groups. However, if the scales are used in non-randomized studies, and any exogenous variables that can cause DIF appear in the studied cohort, one should adjust for the magnitude of the identified DIF [22]. Another approach would be to refrain from items possessing DIF or refrain from using the scales encompassing items possessing DIF [22].

Scales with many items may be preferred, since many items in a scale could increase the sensitivity, specificity, reliability, and ability to discriminate between the groups 
Table 5 Fit statistics, the Cronbach's alpha and discriminating ability of the scales included in the MSQ

\begin{tabular}{|c|c|c|c|c|c|c|c|c|c|}
\hline \multirow[t]{2}{*}{ Scale } & \multirow{2}{*}{$\begin{array}{l}\text { Number } \\
\text { of } \\
\text { items }\end{array}$} & \multicolumn{3}{|c|}{ Fit to Rasch model } & \multicolumn{3}{|c|}{ Fit to log linear Rasch model } & \multirow{2}{*}{$\begin{array}{l}\text { Cronbach's } \\
\text { alpha }\end{array}$} & \multirow[t]{2}{*}{ discriminating ability ${ }^{2}$} \\
\hline & & $x^{2}$ & $d f$ & $P$ & $x^{2}$ & $d f$ & $P$ & & \\
\hline Vaso-motor & 6 & 91.9 & 17 & $<0.0001$ & - & - & - & 0.90 & \\
\hline 1. $\mathrm{HF}$ & 2 & 6.1 & 5 & 0.2941 & 19.7 & 26 & 0.8057 & 0.85 & 30 \\
\hline 2. DNS & 2 & 9.9 & 5 & 0.0778 & 21.6 & 25 & 0.6588 & 0.76 & 34 \\
\hline 3. GS & 2 & 13.6 & 5 & 0.0183 & 13.2 & 17 & 0.7225 & 0.60 & 62 \\
\hline MSSP & 10 & 308.2 & 29 & $<0.0001$ & - & - & - & 0.90 & \\
\hline 4. MSSP & 2 & 6.0 & 5 & 0.3077 & - & - & - & 0.87 & 42 \\
\hline Emotional & 36 & 511.4 & 107 & $<0.0001$ & - & - & - & 0.97 & \\
\hline 5. EM & 12 & 45.1 & 35 & 0.1189 & - & - & - & 0.93 & 158 \\
\hline 6. MEM & 2 & 2.9 & 5 & 0.7176 & - & - & - & 0.90 & 258 \\
\hline SH & 15 & 137.3 & 44 & $<0.0001$ & & & & 0.81 & \\
\hline 7. SH & 8 & 27.7 & 23 & 0.2289 & 61.5 & 71 & 0.7828 & 0.71 & 300 \\
\hline Physical & 25 & 768.6 & 74 & $<0.0001$ & & & & 0.93 & \\
\hline 8. PHY & 8 & 25.1 & 23 & 0.3433 & 87.2 & 73 & 0.1235 & 0.79 & 218 \\
\hline Abdominal & 10 & 219.0 & 29 & $<0.0001$ & & & & 0.81 & \\
\hline 9. ABD & 4 & 13.2 & 11 & 0.2822 & 33.4 & 47 & 0.9260 & 0.63 & 522 \\
\hline Urinary & 6 & 65.8 & 17 & $<0.0001$ & & & & 0.74 & \\
\hline 10. URIN & 4 & 18.7 & 11 & 0.0674 & 7.0 & 32 & 1.0000 & 0.67 & 1040 \\
\hline Sexual & 8 & 230.4 & 31 & $<0.0001$ & & & & 0.95 & \\
\hline 11. SEX & 4 & 15.8 & 15 & 0.3981 & 37.6 & 58 & 0.9825 & 0.91 & 320 \\
\hline
\end{tabular}

${ }^{a}$ Total number of responders needed to show a clinically relevant difference in symptoms (moderate vs. severe bothersome menopause-related symptoms) with an $80 \%$ power and $5 \%$ level of significance. Low numbers indicate a high discriminating ability.

$\mathrm{df}=$ Degrees of freedom, HF = hot flushes, DNS = day-and-night sweats, GS = general sweating, MSSP = menopausal-specific sleeping problems, EM = emotional, MEM = memory, SH = skin-hair, PHY = physical, $A B D=$ abdominal, URIN = urin-vaginal, $S E X=$ sexual

being tested. In the present study, our interest was to assess if the women were "not at all", "a bit", "quite a bit", or "a lot" bothered by menopausal symptoms. We found the best discriminating scales among four 2-item scales: the vasomotor and sleeping scales (HF, DNS, GS and MSSP) and not among scales encompassing more items. There could be two reasons for this lack of discrimination: 1) LD, but even after deleting items with LD, these scales still did not discriminate as well as the scales from the vasomotor and sleeping domains; 2) that the subject matter of the other scales is related more to aging than to menopause.

Due to the large item-pool we identified, we could discharge problematic and poor fitting items using a stepwise procedure. However, we ensured that no important items were lost just because of a psychometric misfit. Therefore, items with high content validity but psychometric misfit were kept as a single item, e.g. item 91 (more tired than usual).

Even though the "work and spare time" domain fitted a Rasch model the items showed poor item fit. Since these items were not symptoms in themselves, but referred to how menopausal symptoms affected women's work and spare time, we decided to disband these items and omit this domain from the final PROM. Moreover, the 3-item menstruation domain did not fit a Rasch model, and as these items were not of high relevance to this study, they were excluded from the final PROM.

Since the timing of menopause and the experience of menopausal symptoms vary so widely $[1,4]$, the MSQ is designed to measure self-reported bothersome menopausal symptoms both in peri- and post-menopausal women. The intention is for the MSQ to be used as an outcome measure in studies where women are treated for bothersome menopausal symptoms. The time needed to complete the MSQ is estimated at $5 \mathrm{~min}$, as the MSQ contains fewer than half the items in the draft PROM.

The MSQ only addresses bothersome menopausal symptoms since these would be the target for treatment. It is important to note that some women also have positive experiences in relation to the menopause [49]; however, this is beyond the scope of the present study. The MSQ was developed in Danish and any new language or modified version may need an additional validation study to secure adequate measurement properties. 


\section{Conclusion}

Menopausal symptoms are multidimensional with only some symptoms unquestionably related to the menopausal transition. The MenoScores Questionnaire (MSQ) is a new, condition-specific PROM with high content validity and adequate psychometrical properties measuring bothersome menopausal symptoms. To the best of our knowledge this is the first PROM measuring only bothersome menopausal symptoms, wherein all scales are developed via interviews with women having bothersome menopausal symptoms and thereafter psychometrically validated using IRT Rasch Models. The focus on bothersome symptoms will assist with identifying and evaluating treatments for women bothered by menopausal symptoms.

\section{Additional files}

Additional file 1: Appendix 1. Unique item-pool (separated into the suggested domains and the new items and domains generated in the interviews). (DOCX $28 \mathrm{~kb}$ )

Additional file 2: Appendix 2. Draft PROM. (DOCX 26 kb)

\begin{abstract}
Abbreviations
ABD: Abdominal; BMS: Bothersome menopausal symptoms; CCT: Classical test theory; Df: Degrees of freedom; DIF: Differential item functioning; DNS: Day-and-night sweats; EM: Emotional; FMP: Final menstrual period; GS: General sweating; HF: Hot flushes; IRT: Item response theory; LD: Local dependency; MEM: Memory; MSQ: MenoScores Questionnaire; MSSP: Menopausal-specific sleeping problems; PHY: Physical; PROM: Patientreported outcome measure; RCT: Randomized controlled trial; SEX: Sexual; SH: Skin-hair; URIN: Urin-vaginal; Wrt: With respect to
\end{abstract}

\section{Acknowledgements}

The authors would like to extend their gratitude to data-manager Dagny Ros Nicolaisdottir for inspiration and counseling, especially in relation to the work with SurveyXact.

\section{Funding}

This study is funded by the Idella Fondation, University of Copenhagen and the Research Fondation of General Practice. Funders have no direct or indirect financial relationships with the authors and no role or authority in decisions about design, collection, management, analyses, interpretation of data, writing of the report or decision about publication.

\section{Availability of data and materials}

The datasets are available from the corresponding author on reasonable request.

\section{Authors' contributions}

All authors have made substantial contributions to the scientific work and the manuscript and have approved the final version of the manuscript.

\section{Ethics approval and consent to participate}

The study was approved by the Danish Data Agency (J.nr. 2015-41-4057). Ethics Committee approval was not required.

\section{Competing interests}

The authors declare that they have no competing interests.

\section{Publisher's Note}

Springer Nature remains neutral with regard to jurisdictional claims in published maps and institutional affiliations.

\section{Author details}

${ }^{1}$ Section of General Practice, Department of Public Health, University of Copenhagen, Øster Farimagsgade 5, Q, P.O. Box 2099, 1014 Copenhagen K, Denmark. ${ }^{2}$ The Research Unit of General Practice, Department of Public Health, University of Copenhagen, Øster Farimagsgade 5, Q, 1014 Copenhagen K, Denmark. ${ }^{3}$ Section of Biostatistics, Department of Public Health, University of Copenhagen, Øster Farimagsgade 5, Building 15 (15-2-12), P.O. Box 2099, DK-1014 Copenhagen K, Denmark. ${ }^{4}$ The Research Unit for General Practice, Department of Public Health, University of Southern Denmark, J.B. Winsløws Vej 9, 5000 Odense C, Denmark. ${ }^{5}$ Primary Health Care Research Unit, Region Zealand, 4180 Alleen 15, Sorø, Denmark.

Received: 12 October 2017 Accepted: 7 May 2018

Published online: 16 May 2018

References

1. Nelson HD. Menopause. Lancet. 2008;371:760-70.

2. Harlow SD, Gass M, Hall JE, Lobo R, Maki P, Rebar RW, et al. Executive summary of the stages of reproductive aging workshop +10 : addressing the unfinished agenda of staging reproductive aging. Clin Endocrinol Metab. 2012;97(4):1159-68.

3. Sarri $G$, Davies M, Lumsden MA. Diagnosis and management of menopause: summary of NICE guidance. BMJ. 2015;351:1-6.

4. Domoney $\mathrm{CL}$, Vashisht A, Studd JW. Use of complementary therapies by women attending a specialist premenstrual syndrome clinic. Gynecol Endocrinol. 2003:17(1):13-8.

5. Stearns V, Ullmer L, Lopez JF, et al. Hot flushes. Lancet. 2002;360:1851-61.

6. Avis NE, Crawford SL, Greendale G, Bromberger JT, Everson-Rose SA, Gold $E B$, et al. Duration of menopausal vasomotor symptoms over the menopause transition. JAMA Intern Med. 2015;175(4):531-9.

7. Pachman DR, Jones JM, Loprinzi CL. Management of menopause-associated vasomotor symptoms: current treatment options, challenges and future directions. Int J Women's Health. 2010;2:123-35.

8. Pearce J, Hawton K, Blake F. Psychological and sexual symptoms associated with the menopause and the effects of hormone replacement therapy. $\mathrm{Br} J$ Psychiatry. 1995; 167:163-73.

9. Nappi RE, Lachowsky M. Menopause and sexuality: prevalence of symptoms and impact on quality of life. Maturitas. 2009;63(2):138-41.

10. Prairie BA, Wisniewski SR, Luther J, Hess R, Thurston RC, Wisner KL. Symptoms of depressed mood, disturbed sleep, and sexual problems in midlife women: cross-sectional data from the study of Women's health across the nation. J Women's Health. 2015;24(2):119-26.

11. Col NF, Guthrie JR, Politi M, Dennerstein L. Duration of vasomotor symptoms in middle-aged women: a longitudinal study. Menopause. 2009;16(3):453-7.

12. Green R, Polotsky AJ, Wildman RP, McGinn AP, Lin J, Derby C, et al. Menopausal symptoms within a Hispanic cohort: SWAN, the study of women's health across the nation. Climacteric. 2010;13(4):376-84.

13. Avis NE, Stellato R, Crawford S, Bromberger J, Ganz P, Cain V, et al. Is there a menopausal syndrome? Menopausal status and symptoms across racial/ ethnic groups. Soc Sci Med. 2001;52(3):345-56.

14. Kreiner S, Christensen KB. Validity and objectivity in health-related scales: analysis by graphical loglinear Rasch models. In: von Davier M, Carstensen $\mathrm{CH}$, editors. Multivariate and mixture distribution Rasch models. New York: Springer; 2007. p. 329-46.

15. Streiner DL, Norman GR. Heath measurement scale, a practical guide to their develpment and use. 4th ed. Oxford: Oxford University Press; 2008.

16. Mokkink LB, de Vet HCW, Prinsen CAC, Patrick DL, Alonso J, Bouter LM, et al. COSMIN risk of Bias checklist for systematic reviews of patient-reported outcome measures. Quality of life research: an international journal of quality of life aspects of treatment, care and rehabilitation. 2018;27(5):1171-9.

17. Comins JD, Krogsgaard MR, Brodersen J. Ensuring face validity in patientrelated outcome scores-a matter of content. Knee. 2013;20(2):72-8.

18. Forskningsenheden for almen praksis. http://almenpraksis.ku.dk/forskning/ menopause/menopause. Accessed May 2017.

19. Magasinet liv. http://magasinetliv.dk. Accessed May 2017.

20. Masters GN. A Rasch model for partial credit scoring. Psychometrika. 1982; 47(2):149-74.

21. Holland PWWH. Differential item functioning. Hillsdale: Erlbaum; 1993.

22. Brodersen JMD, Kreiner S, Thorsen H, Doward L, McKenna S. Methodological aspects of differential item functioning in the Rasch model. J Med Econ. 2007;10:309-24. 
23. Christensen KB, Makransky G, Horton M. Critical values for Yen's Q 3: identification of local dependence in the Rasch model using residual correlations. Appl Psychol Meas. 2017:41(3):178-94.

24. Kreiner $\mathrm{S}$, Christensen KB. Item screening in graphical loglinear Rasch models. Psychometrika. 2011;76(2):228-56.

25. Kelderman H. Loglinear Rasch model tests. Psychometrika. 1984;49(2):223-45.

26. Andersen EB. A goodness of fit test for the Rasch model. Psychometrika. 1973;38(1):123-40.

27. Kreiner S. A note on item-restscore association in Rasch models. Appl Psychol Meas. 2011;35(7):557-61.

28. Cronbach $L$. Coefficient alpha and the internal structure of tests. Psychometrika. 1951;16(3):297-334.

29. Cronbach L. Internal consistency of tests: analyses old and new. Psychometrika. 1988;53(1):63-70.

30. Benjamini $Y$, Hochberg $Y$. Controlling the false discovery rate: a practical and powerful approach to multiple testing. J R Stat Soc Ser B Methodol. 1995;57(1):289-300.

31. Kupperman HS, Blatt MH, Wiesbader H, Filler W. Comparative clinical evaluation of estrogenic preparations by the menopausal and amenorrheal indices. J Clin Endocrinol Metab. 1953;13(6):688-703.

32. Alder E. The blatt-Kupperman menopausal index: a critique. Maturitas. 1998;29:19-24.

33. Tao M, Shao H, Li C, Teng Y. Correlation between the modified Kupperman index and the menopause rating scale in Chinese women. Patient Prefer Adherence. 2013;7:223-9.

34. Bech P, Munk-Jensen N, Obel E, Ulrich L, Eiken P, Nielsen SP. Combined versus sequential hormonal replacement therapy: a double-blind, placebocontrolled study on quality of life-related outcome measures. Psychother Psychosom. 1998;67(4-5):259-65.

35. Greene JG. A factor analytic study of climacteric symptoms. J Psychosom Res. 1976;20(5):425-30.

36. Greene JG. Constructing a standard climacteric scale. Maturitas. 2008;61(1-2):78-84.

37. Hunter M. The Women's health questionnaire (WHQ): the development, standardization and application of a measure of mid-aged women's emotional and physical health. Qual Life Res. 2000;9(1):733-8.

38. Hunter MS. The Women's health questionnaire (WHQ): frequently asked questions (FAQ). Health Qual Life Outcomes. 2003;1:41.

39. Hilditch JR, Lewis J, Peter A, van Maris B, Ross A, Franssen E, et al. A menopause-specific quality of life questionnaire: development and psychometric properties. Maturitas. 2008;61(1-2):107-21.

40. Lewis JE, Hilditch JR, Wong CJ. Further psychometric property development of the menopause-specific quality of life questionnaire and development of a modified version, MENQOL-Intervention questionnaire. Maturitas. 2005; 50(3):209-21.

41. Perz JM. Development of the menopause symptom list: a factor analytic study of menopause associated symptoms. Women Health. 1997;25(1):53-69.

42. Heinemann K, Ruebig A, Potthoff P, Schneider HP, Strelow F, Heinemann $L A$, et al. The menopause rating scale (MRS) scale: a methodological review. Health Qual Life Outcomes. 2004;2:45.

43. Perez-Lopez FR, Fernandez-Alonso AM, Perez-Roncero G, Chedraui P, Monterrosa-Castro A, Llaneza P. Assessment of menopause-related symptoms in mid-aged women with the 10-item Cervantes scale. Maturitas. 2013;76(2):151-4.

44. Brazier JE, Roberts J, Platts M, Zoellner YF. Estimating a preference-based index for a menopause specific health quality of life questionnaire. Health Qual Life Outcomes. 2005;3:13.

45. Neugarten BL, Kraines RJ. "MENOPAUSAL SYMPTOMS" IN WOMEN OF VARIOUS AGES. Psychosom Med. 1965;27:266-73.

46. Hvas $L$, Thorsen $H$, Sondergaard K. Discussing menopause in general practice. Maturitas. 2003:46(2):139-46

47. Jacobs PA, Hyland ME, Ley A. Self-rated menopausal status and quality of life in women aged 40-63 years. Br J Health Psychol. 2000:5:395-411.

48. Lund KS, Brodersen J, Siersma V, Waldorff FB. The efficacy of acupuncture on menopausal symptoms (ACOM study): protocol for a randomised study. Dan Med J. 2017:64(3):A5344.

49. Hvas L. Positive aspects of menopause: a qualitative study. Maturitas. 2001; 39(1):11-7.

\section{Ready to submit your research? Choose BMC and benefit from:}

- fast, convenient online submission

- thorough peer review by experienced researchers in your field

- rapid publication on acceptance

- support for research data, including large and complex data types

- gold Open Access which fosters wider collaboration and increased citations

- maximum visibility for your research: over $100 \mathrm{M}$ website views per year

At BMC, research is always in progress.

Learn more biomedcentral.com/submissions 